\title{
Does the past spell out the future?
}

\author{
Current anxieties about the prospect of climatic change, as a consequence of the carbon dioxide \\ greenhouse or other means, raise important questions about the limitations of statistical inference.
}

CAN a journal with the title Climatic change fairly claim to be objective? That quizzical question, born of the suspicion that the title is meant to suggest the climate must be changing when it may not be, should be struck down. For one thing, journals can call themselves by the titles with which they are most comfortable, and should ordinarily choose titles that seem to suit them best. For another, there is a continuing and serious interest in the prospect that the present climate may be unstable, first stimulated by the recognition that the coldest spell in the most recent glaciation was merely 18,000 years ago, when the English Channel was dry land.

It is entirely proper that people impressed by that and other observations of the fragility of our climate should contribute articles to a journal entitled Climatic change. It is also natural, in the circumstances, that many (but by no means all) of the contributors should be concerned with the possible effects of carbon dioxide on the terrestrial climate. But the journal also raises implicitly (and sometimes explicitly) the interesting question of the degree to which it is permissible to predict what the future holds for climate on the basis of observations of the past.

The occasion for this introspection is an article by R.P. Kane from Brazil's Institute of Space Research, now under the wing of the ministry of science and technology, with the arresting title "Are droughts predictable". The essence of the argument is that they are predictable in some parts of the world, but not everywhere. Starting with records of precipitation going back for decades, the authors conclude that there are, indeed, some parts of the world where dry spells have recurred at regular intervals. These include north-east Africa and north-east Brazil.

The criterion for deciding when future predictions of drought should be taken as reliable is that past fluctuations of rainfall should stand out from statistical noise by at least two standard deviations, perhaps even three. Moreover, it should not be thought that short-term fluctuations (with periods of two or three years) are reliable indicators, given their probable connection with what is called the quasi-biennial oscillation (linked, among other things, with the El Nino phenomenon). But, with these reservations, the article does go on to support its author's decision to declare where and when there will be serious droughts by means of brackets beneath graphs which are time-series of recorded rainfall at different places.

The article is really quite disarming. Looking back, the authors note that when, in 1978, C. Giradi and L. Teixeira from Sao Paulo published a prediction that there would be a drought in northeast Brazil between 1978 and 1983, "Giradi gave interviews to the press, which gave due publicity to his views", that the "government ... and the meteorological community ignored his views", but that, "nevertheless, the drought occured...". Plainly, there is no future in being a prophet, especially in one's own country. Kane and Trivedi go on to say that they have no wish to "scare people as by crying wolf" and that they expect that the precautions taken by people heeding their warnings will be harmless in the sense that if the predicted droughts arrive, "the precautionary measures would come in handy", but that if the droughts do not arrive, "no harm would occur".

To give the show away, the Kane and Trivedi article is exactly two years old (Climatic change $\mathbf{8}, 209 ; 1986$ ). That is too soon to know whether the particular predictions have been sustained - many of the droughts predicted will not arrive until the middle-1990s. But the philosophical issue raised by the article is even more important now than then: when can it be both prudent and useful to make predictions of natural phenomana? Droughts and earthquakes are obvious examples, but current interest in the greenhouse effect expected to follow from the accumulation of atmospheric carbon dioxide is the most obvious illustration.

Perceptively, Climatic change, recognizing the solemnity with which predictions must be regarded, invited A. Barrie Pittock from the CSIRO Division of Atmospheric Research near Melbourne, and a member of its editorial board, to comment on what it had done. Pittock, prominent among those who a few years ago were warning people of the hazards of the nuclear winter that may follow all-out nuclear war, makes an exceedingly intelligent and interesting comment on the drought predictions from Brazil, a revealing comment about nuclear winter, an ambiguous but implicit comment on proper attitudes towards the greenhouse effect and a helpful comment on the problem of statistical inference in general. Too little attention has been paid to the last of these in recent discussions of the last-but-one.

First, there is the general principle that statistical analyis can only test the validity of hypotheses, not prove them to be correct. Moreover, there is always a confidence limit involved, explicitly or otherwise: is 5 per cent ( 95 per cent) sufficient, is it necessary to go to 1 per cent ( 99 per cent) or is the expected degree of confidence a measure of the subjective level at which one's data are likely to be significant? Pittock rightly declares that arguments such as these melt away only when the problem of inferring the truth about the real world is simplified by the arrival of a physical mechanism connecting the future with the past. If we did not know about the Solar System, we should be a little at a loss to know what to make of the diurnal rising of the sun, millenia of observations notwithstanding.

Statisticians have long been familiar with an even more teasing problem in statistical inference, that of accounting for the different behaviour of people when confronted with the same statistical evidence. Bad news about cigarette smoking has persuaded many people to give up the habit, but others apparently believe the inferences that might be drawn do not apply to them. Pittock puts the point differently by noting that on a prediction of a 40 per cent probability of rain, some people will carry umbrellas and others not, and then by remarking that the distinction is not simply one between pessimists and optimists, but that the circumstances matter; if one is off to swim, one can afford to be an optimist about the rain.

How does this apply to climate prediction? Pittock says that science "acts to protect the correctness of what is considered as established scientific knowledge" and thus rejects hypotheses until proven. But in the real world, he says, it may be "socially responsible to urge action on the basis of a hypothesis ... not proven beyond reasonable doubt". That is where nuclear winter comes in. (Kane and Trivedi come poorly out of this, for acting on false warnings could cause "a lot of unecessary expense and suffering".)

The most worrying aspect of this is that it is a licence for allowing undeclared and subjective calculations of consequences to influence pronouncements. In the argument about the greenhouse that lies ahead, it may be prudent to ask the experts who testify on both sides what their hidden calculations are. John Maddox 